\title{
Identification of a GTPase-Activating Protein Homolog in Schizosaccharomyces pombe
}

\author{
YOSHIYUKI IMAI, ${ }^{1}$ SANAE MIYAKE, ${ }^{2}$ DAVID A. HUGHES, ${ }^{1}$ AND MASAYUKI YAMAMOTO ${ }^{1 *}$ \\ Department of Biophysics and Biochemistry, Faculty of Science, University of Tokyo, P.O. Hongo, Tokyo $113,{ }^{1}$ and \\ Laboratory of Molecular Genetics, Institute of Medical Science, University of Tokyo, P.O. Takanawa, Tokyo 108, ${ }^{2}$ Japan
}

Received 4 February 1991/Accepted 25 March 1991

\begin{abstract}
Loss of function of the Schizosaccharomyces pombe gap1 gene results in the same phenotypes as those caused by an activated ras 1 mutation, i.e., hypersensitivity to the mating factor and inability to perform efficient mating. Sequence analysis of gap1 indicates that it encodes a homolog of the mammalian Ras GTPase-activating protein (GAP). The predicted gap1 gene product has 766 amino acids with relatively short $\mathrm{N}$ - and $\mathrm{C}$-terminal regions flanking the conserved core sequence of GAP. Genetic analysis suggests that $S$. pombe Gap1 functions primarily as a negative regulator of Ras1, like $S$. cerevisiae GAP homologs encoded by IRAI and IRA2, but is unlikely to be a downstream effector of the Ras protein, a role proposed for mammalian GAP. Thus, Gap1 and Ste6, a putative GDP-GTP-exchanging protein for Ras1 previously identified, appear to play antagonistic roles in the Ras-GTPase cycle in $S$. pombe. Furthermore, we suggest that this Ras-GTPase cycle involves the ral2 gene product, another positive regulator of Ras1 whose homologs have not been identified in other organisms, which could function either as a second GDP-GTP-exchanging protein or as a factor that negatively regulates Gap1 activity.
\end{abstract}

Schizosaccharomyces pombe has only one homolog of mammalian ras $(14,31)$. This gene, rasl, is essential for mating but not for vegetative growth $(16,30)$, whereas Saccharomyces cerevisiae RAS1 and RAS2 are essential for cell cycle progression $(24,40)$. $S$. cerevisiae Ras proteins regulate adenylyl cyclase activity (41), but $S$. pombe Ras1, like mammalian Ras proteins $(5,6,26)$, does not (16). Despite these differences, genes involved in activation of Ras proteins, namely, $S$. cerevisiae $C D C 25(8,11,33)$ and $S$. pombe ste6 (22), are homologous in the two distantly related yeasts. Furthermore, the product of ral2, whose deficiency causes phenotypes similar to those caused by the rasl mutation (18), has been proposed as an additional Ras1 activator in $S$. pombe (17).

The activity of Ras protein is thought to be regulated by both positive and negative factors (see reference 7 for a review). Mammalian cells have a protein that stimulates GTPase activity of Ras (GTPase-activating protein [GAP]) as a negative regulator (42-44) and may also function as an effector of Ras $(1,10,29)$. Another protein, encoded by $N F 1$, is homologous to GAP and can stimulate Ras GTPase activity $(3,9,28,46,47)$. S. cerevisiae IRAI and IRA2 encode proteins homologous to both GAP and NFI and function as negative regulators of Ras (37-39), but no evidence for their function as an effector of Ras has been obtained. While putative activators of $S$. pombe Ras1, namely, ste6 and ral2, have been identified, no negative regulator of Ras1 has been reported for this eukaryotic microbe. During our attempts to identify elements that may interact with $S$. pombe Ras1, we identified a gene, gapl, which apparently regulates Ras 1 negatively. The deduced gapl gene product has a region homologous to the catalytic domain of mammalian GAP $(27,42-44)$. We report here the characterization and genetic analysis of gapl, which suggest that $S$. pombe Gap1 is likely to be a negative regulator, but not a downstream effector, of Ras1.

* Corresponding author.

\section{MATERIALS AND METHODS}

Strains, media, genetic methods, and transformation of $S$. pombe. The $S$. pombe strains used in this study are listed in Table 1 . The media $(13,20,45)$ and general genetic methods (20) used for $S$. pombe have already been described. Mutagenesis of $S$. pombe cells with $N$-methyl- $N^{\prime}$-nitro- $N$-nitrosoguanidine was performed essentially as described before (23). Transformation of $S$. pombe cells was done by a high-efficiency protocol recently developed (32).

Cloning of gap1. S. pombe JZ429 $\left(h^{90}\right.$ gapl-1 ade6-M210 leul) was transformed with a library constructed with Sau3AI partial digests of $S$. pombe genomic DNA in vector pDB248' (4). Leu ${ }^{+}$transformants were tested for mating and sporulation by exposure to iodine vapor, which stains spores dark brown (20). Three plasmids with overlapping inserts, one of which is pST200-1 (Fig. 1), were recovered from transformants that formed zygotic asci. A subclone of pST200-1 carrying a 3.4-kb EcoRV-Sau3AI fragment was able to complement JZ429.

Nucleotide sequence determination. The DNA sequence of the 3.4-kb EcoRV-Sau3AI fragment was determined by using the dideoxy-chain termination method (35). Subclones for sequencing were generated by progressive deletion with exonuclease III and S1 nuclease (21) from clones in plasmid pUC119. Single-stranded DNA was prepared by using M13KO7 as a helper bacteriophage. The region shown in Fig. 2 was sequenced in both directions at least once:

Gene disruption. One-step gene disruption (34) of gapl was carried out as follows. A 2.0-kb KpnI-HindIII fragment was removed from the open reading frame (ORF), and an $S$. pombe $\mathrm{ura}^{+}$cassette (19) was inserted. An XhoI-XbaI fragment carrying the disrupted gene was used to transform $S$. pombe JY878 ( $h^{90}$ ade6-M216 leul ura4-D18). Most of the stable $\mathrm{Ura}^{+}$transformants were sterile. Precise replacement of the wild-type allele by the $u r a 4^{+}$-disrupted gene was confirmed by Southern blot analysis.

Mating assay. Qualitative assay of mating was done by iodine vapor staining (20). Determination of mating effi- 
TABLE 1. $S$. pombe strains used

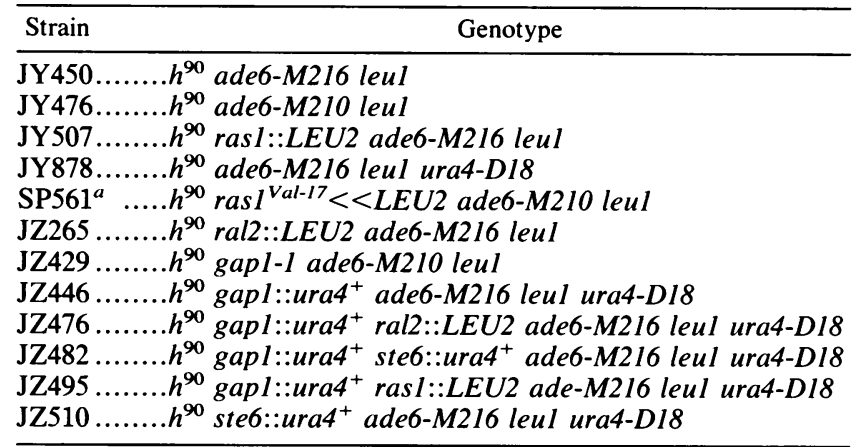

${ }^{a}$ The expression rasI ${ }^{\text {Val-17 }}<<L E U 2$ indicates that the $S$. cerevisiae LEU2 gene is integrated in the vicinity of the ras I $^{\text {Val-17 }}$ allele on the chromosome. This strain was obtained from S. Nadin-Davis (30).

ciency was done in two ways. (i) Cells to be crossed were placed in a patch on plates for mating and incubated at $30^{\circ} \mathrm{C}$ for 24 to $48 \mathrm{~h}$. Mating efficiency was calculated by counting the numbers of zygotes, asci, spores, and unmated cells in the mixture under a microscope. (ii) A strain to be tested and the mating partner carried the ade6-M210 and ade6-M216 markers, respectively, or vice versa. These two ade6 markers complement intragenically (20). Cells were crossed, and the number of adenine prototrophs, i.e., diploid cells generated by mating, was determined. This method was less quantitative but was essential for detection of the lowfrequency mating displayed by gapl or ras $1^{\text {Val-17 }}$ cells, which could not be detected by the first method.

\section{RESULTS}

Isolation of gapl mutants. $S$. pombe cells extend conjugation tubes in response to the mating factor secreted by the
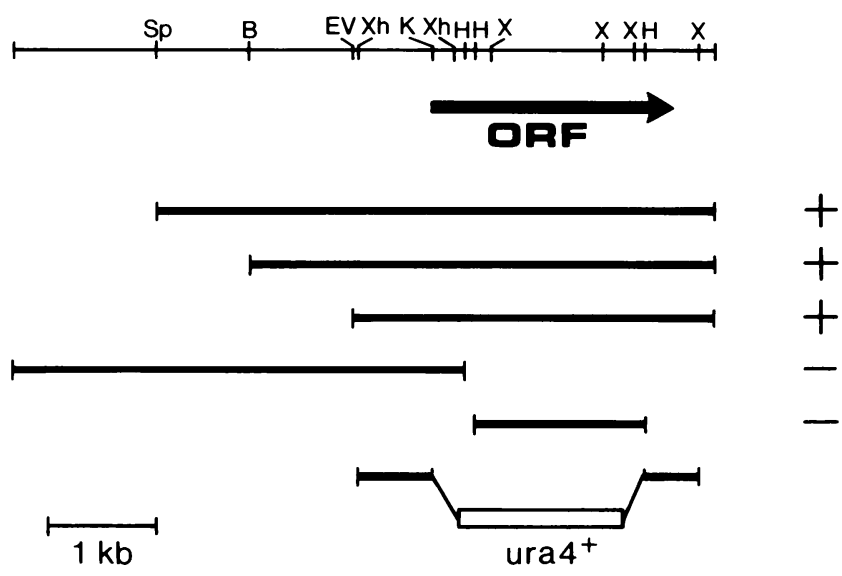

FIG. 1. Cloning and disruption of the gapl gene. A restriction map of the insert DNA in plasmid pST200-1 is shown with the extent and direction of the gapl ORF indicated by the arrow. Restriction sites: B, BamHI; EV, EcoRV; H, HindIII; K, KpnI; Sp, SphI; X, $X b a I ; X h, X h o I$. Restriction fragments of pST200-1 were subcloned in pDB248' (4), and their abilities to complement JZ429 were tested. The ability of a subclone to rescue the mating deficiency of gapl-Icarrying cells is indicated as a plus or a minus. The structure of the linear fragment used to disrupt the gapl gene in vivo is shown at the foot of the figure. The open box stands for an $S$. pombe ura $4^{+}$ cassette (19).

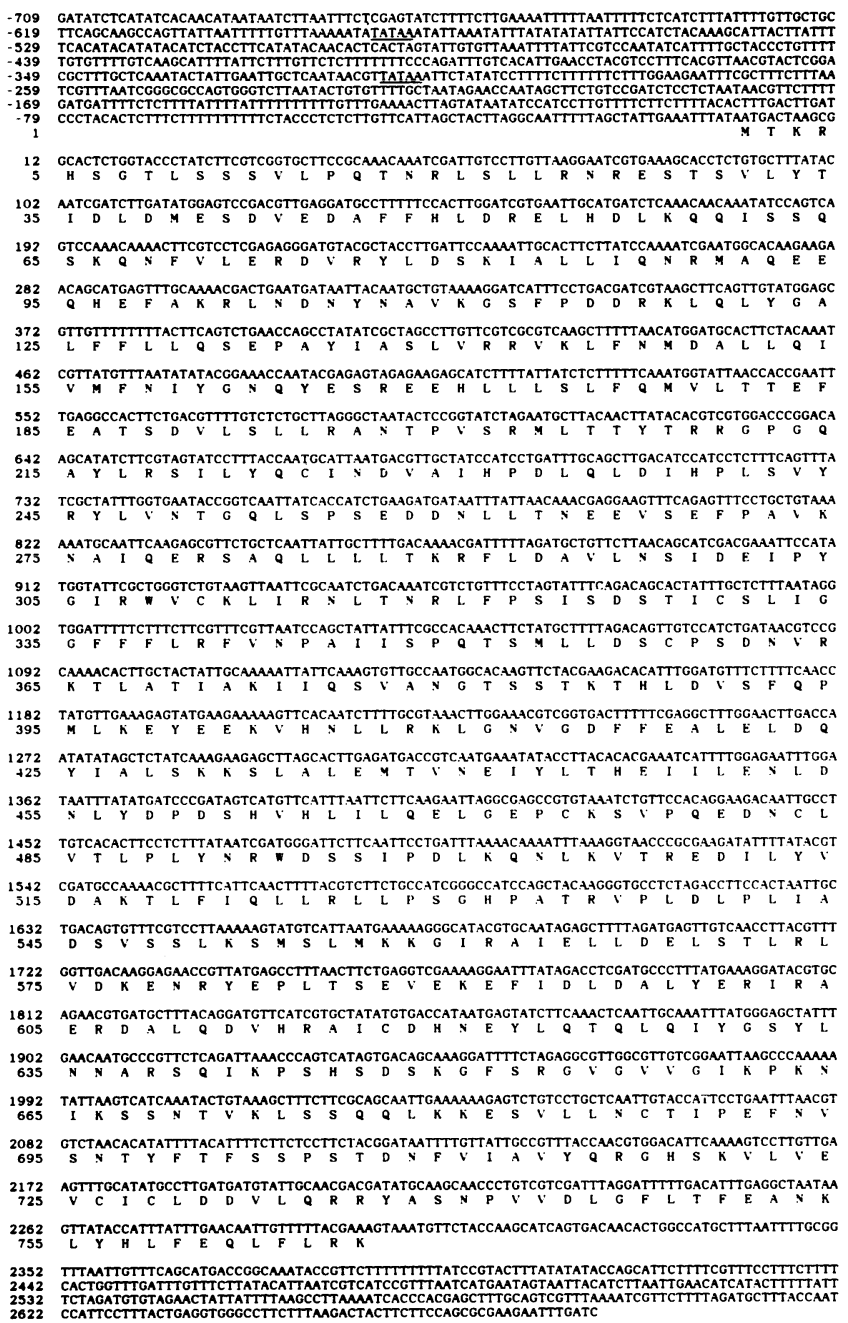

FIG. 2. DNA sequence and corresponding deduced amino acid sequence (single-letter code) of the gapl gene. The DNA sequence of a 3,392-base EcoRV-Sau3AI fragment that could encode a 2,298-base ORF is shown. The deduced amino acid sequence is shown below the DNA sequence. Numbering starts with the first methionine codon in the ORF. Possible TATA elements in the $5^{\prime}$ region of the gene are underlined.

mating partner, although the response of $h^{+}$cells to the M mating factor is more apparent than that of $h^{-}$cells to the $\mathbf{P}$ mating factor $(15,25)$. Homothallic rasI $I^{\mathrm{Val}-17}$ mutant cells are hypersensitive to the mating factor and form excessively elongated conjugation tubes, but successful mating is greatly impaired although not entirely inhibited $(16,30)$. We expected that mutations in elements that are involved in Ras1 activation could exhibit phenotypes similar to those of ras $I^{\text {Val-17}}$ cells. Thus, we set out to isolate $S$. pombe mutants that exhibit such phenotypes.

Homothallic haploid cells were mutagenized and placed on malt extract-agar plates, on which wild-type cells proliferate to form small colonies and then undergo mating and sporulation because of a limited nitrogen supply. Sporulation-defective mutants were screened by exposure to iodine vapor, which stains spores dark brown (20), and matingdeficient but mating factor-hypersensitive mutants were chosen by inspection under a microscope. Thirteen mutants 
TABLE 2. Amino acid identities between GAP homologs in the conserved core region ${ }^{a}$

\begin{tabular}{lcccc}
\hline \multirow{2}{*}{ Protein } & \multicolumn{4}{c}{ \% Identity with: } \\
\cline { 2 - 5 } & Ira1 & Ira2 & NF1 & GAP \\
\hline S. pombe Gap1 & 24.6 & 15.9 & 19.7 & 19.7 \\
Ira1 & & 51.7 & 25.3 & 22.5 \\
Ira2 & & & 26.5 & 21.3 \\
NF1 & & & & 27.5 \\
\hline
\end{tabular}

${ }^{a}$ The regions compared are shown as solid boxes in Fig. 3. Original sequence reports: Ira1, reference 37; Ira2, reference 39; NF1, references 9 and 47; GAP, references 43 and 44 .

showing phenotypes similar to those of $\mathrm{rasl}^{\mathrm{Val}-17}$ cells were isolated among 80,000 mutagenized cells and genetically classified into three linkage groups (sxal, sxa2, and gapl). Only one mutant (gapl-1) mapped in gapl in this analysis. Seven more mutant alleles of gapl were isolated as suppressors of the ral2 mutation (see below).

Cloning of gap1. The gapl gene was cloned from an $S$. pombe genomic library by complementation of the gapl-1 mutant with selection for mating proficiency. A restriction map of the original clone, pST200-1, is shown in Fig. 1 . The essential region for complementation was delimited by subcloning. A 3.4-kb EcoRV-Sau3AI fragment was sufficient for complementation (Fig. 1). Nucleotide sequence analysis of this region revealed an ORF of 766 amino acids (Fig. 2). Northern (RNA) blot analysis showed that the gapl gene is transcribed into $3.1 \mathrm{~kb}$ of mRNA (data not shown).

The deduced amino acid sequence of Gap1 was compared with the EMBL/GenBank/DDBJ data base (Table 2). This gene product had the highest homology $(19.7 \%$ overall amino acid identity) with $S$. cerevisiae Iral (37), which is a yeast homolog of mammalian GAP. It was obvious that $S$. pombe Gap1 has the conserved core sequence seen in mammalian GAP and its homologs (Table 2 and Fig. 3). S. pombe Gap1 has relatively short sequences flanking the conserved core, and these sequences are weakly homologous to $S$. cerevisiae Ira1 and Ira2 $(37,39)$ and human NF1 $(9,47)$ (Fig. 3$)$. The implication of this structural feature will be considered in the Discussion.

Gene disruption. Disruption of the gapl gene by insertion of an $S$. pombe ura4 $4^{+}$cassette was carried out in homothallic

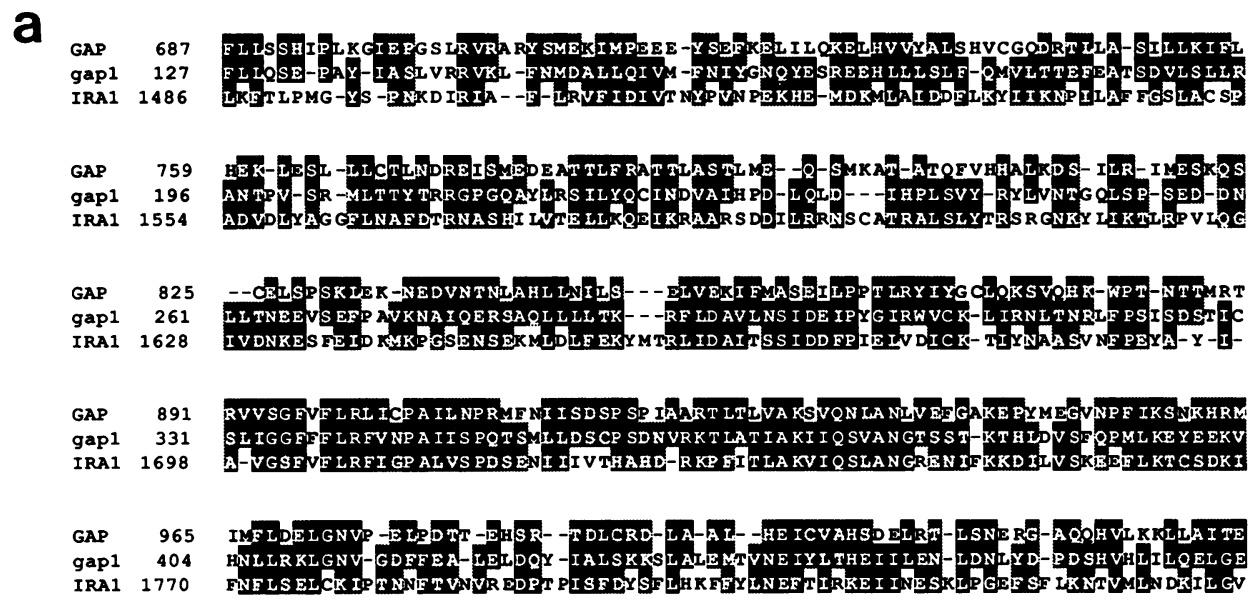

b

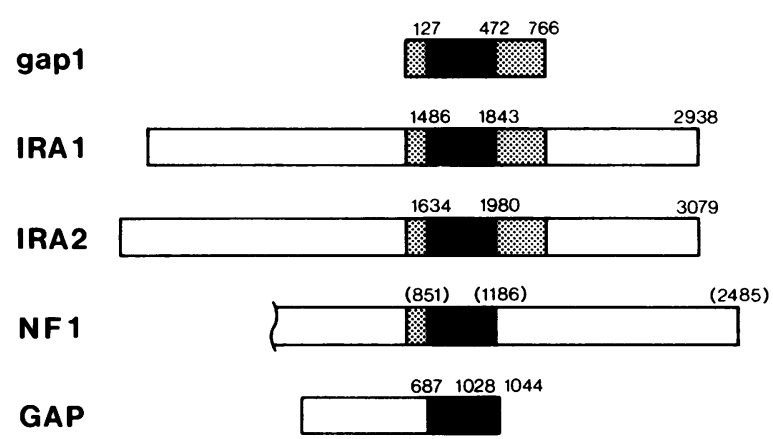

FIG. 3. (a) Comparison of amino acid sequences of the core regions in mammalian GAP, the $S$. pombe gapl gene product, and the $S$. cerevisiae IRAI gene product. Identical amino acids are shown in white against black, and conserved amino acids, in accordance with the mutation data of Dayhoff et al. (12), are shown in white against grey. (b) Schematic illustration of the protein structures of GAP homologs. The solid boxes represent conserved core sequences in which Gapl and mammalian GAP have homology and regions in other homologs that correspond to them. This region is nearly identical to the catalytic domain assigned in mammalian GAP (27). The homology between each pair of the members in this core region is summarized in Table 2. IRA1 and IRA2 are weakly homologous to gap1 in regions flanking the core (10 to $20 \%$ amino acid identity), which are shown as dotted boxes. The leftward flanking region in NF1 also has weak homology to gap1. Outside of these regions, IRA1, IRA2, and NF1 share homology which is not indicated here. Relevant amino acid positions are numbered for each protein. The numbering for NF1 is tentative. 
haploid cells by a gene replacement procedure (34), and gapl::ura $4^{+}$derivatives were obtained. The structure of the linear fragment used to disrupt the gapl gene is shown at the foot of Fig. 1, and the experimental details are described in Materials and Methods. Precise replacement of the wild-type allele by the $u r a 4^{+}$-disrupted gene was demonstrated in some of the transformants by Southern blot analysis (data not shown). One such disruptant (JZ446) was fused with JZ429 by protoplast fusion (36), and sporulation was induced in resultant diploid cells. All of more than 500 progeny spores tested were sterile, indicating tight linkage of the disrupted gene and gapl.

Genetic interaction of gapl with other genes. The gapl disruptants showed the same phenotypes as the original gapl-1 mutant, indicating that loss of gapl function confers phenotypes similar to those conferred by activated ras 1 . Cells disrupted in both gapl and rasl showed the same phenotypes as rasl disruptants and were completely sterile (Fig. 4). These observations suggest that the gapl null mutation causes its effects through Ras1 and that Gap1 can be an upstream negative regulator of the Ras protein but not an effector regulated by Ras 1 . The latter is a role proposed for mammalian GAP $(1,10,29)$.

Two putative Ras1 activators have been identified in $S$. pombe. One of them, ste6 (22), is homologous to $S$. cerevisiae $C D C 25(8,11,33)$, and its product is likely to be a GDP-GTP exchange protein for Ras1. It is unclear how the other, ral2 (17), is involved in activation of Ras1. Null mutations in either of these genes made cells completely sterile and insensitive to the mating factor (Fig. 4). This insensitivity is suppressed by the activated mutations in ras 1 in both cases, and the resultant cells become weakly mating proficient $(17,22)$. We examined phenotypes of double mutants defective in gapl and ste6 or gapl and ral2. Such mutants had essentially the same phenotype as gapl mutant cells (Fig. 4) and could mate, although very poorly. Thus, the gapl and activated rasl mutations were equivalent in these analyses. A gapl ste6 ral2 triple mutant also showed the same phenotype as gapl mutant cells (data not shown). These observations suggest that the ste6 and ral2 gene products are no longer necessary to fix the Ras protein in its GTP-bound form once Gap1 activity is lost.

We isolated eight independent ral2 suppressor mutants that were weakly fertile and hypersensitive to the mating factor. Consistent with the above-described observations, seven of them had mutations in gapl, suggesting intimate interaction between ral2 and gapl, while the eighth had acquired an activating mutation in rasl (data not shown).

\section{DISCUSSION}

This work has demonstrated that $S$. pombe has a homolog of mammalian GAP. Genetic analysis strongly suggested that this homolog, Gap1, negatively regulates Ras1 activity. One feature of Gap1 was its small size (766 amino acids). $S$. cerevisiae GAP homologs, namely, Ira1 and Ira2, are much larger, having nearly 3,000 amino acids, and Gap1 corresponds only to their central domain. Mammalian GAP is larger than Gap1 by about 300 amino acids, and its N-terminal region carries two copies of the $S r c$ homology 2 domain, which has been suggested to be the site for interaction with activated growth factor receptors (2). S. pombe Gap1 does not have an $S r c$ homology 2 sequence. These structural differences suggest that regulation of $S$. pombe Gap1 activity, if any, is different from and probably simpler than that of
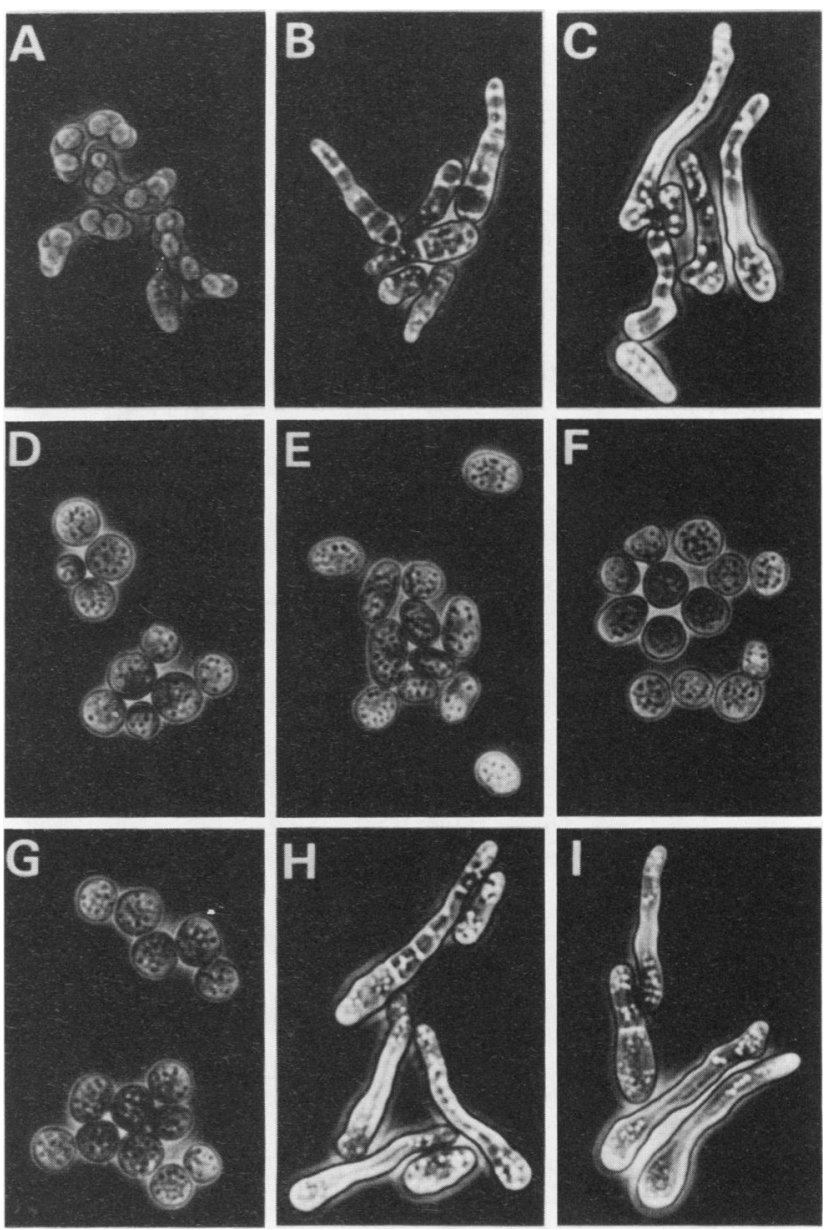

FIG. 4. Cell morphology of various mutants under nitrogen starvation. Panels: A, JY450 (wild type); B, SP561 (ras1 ${ }^{\text {Val-17 }}$ ); C JZ446 (gapl mutant); D, JY507 (rasI mutant); E, JZ510 (ste6 mutant); F, JZ265 (ral2 mutant); G, JZ495 (rasl gapl mutant); H, JZ482 (ste6 gapl mutant); I, JZ476 (ral2 gapl mutant). All of the cells shown here are homothallic $\left(h^{90}\right)$ haploid, and the mutations indicated stand for disrupted nonfunctional alleles, except for rasl ${ }^{\text {Val-17 }}$. Cells were placed on malt extract-agar plates which contained only a limited nitrogen source and incubated at $30^{\circ} \mathrm{C}$ for 2 days. Cell morphology was examined by phase-contrast microscopy, and photographs were taken. Mating and subsequent sporulation were successful in control A. The cells shown in panels B, C, $\mathrm{H}$, and I extended conjugation tubes excessively, whereas the cells in panels $\mathrm{D}, \mathrm{E}, \mathrm{F}$, and $\mathrm{G}$ were completely inert. Bar, $10 \mu \mathrm{m}$.

the other GAP homologs. We found that the putative catalytic domain of Gap1 alone (Met-148 to Arg-492 [Fig. 2]) was sufficient to confer mating proficiency on gapl mutant cells (data not shown), although complementation by the truncated gene was slightly weaker than that by the intact gene. On the basis of these observations, we suggest that $S$. pombe Gap1 has a rather simple function not connected with the effector function, i.e., to down regulate the level of Ras GTP.

Combined with our previous finding that Ste6 is an activator of Ras1 homologous to $S$. cerevisiae $\operatorname{Cdc} 25$ (22), we can illustrate the Ras GTPase cycle in $S$. pombe as shown in Fig. 5. The cycle is essentially the same as that of $S$. 

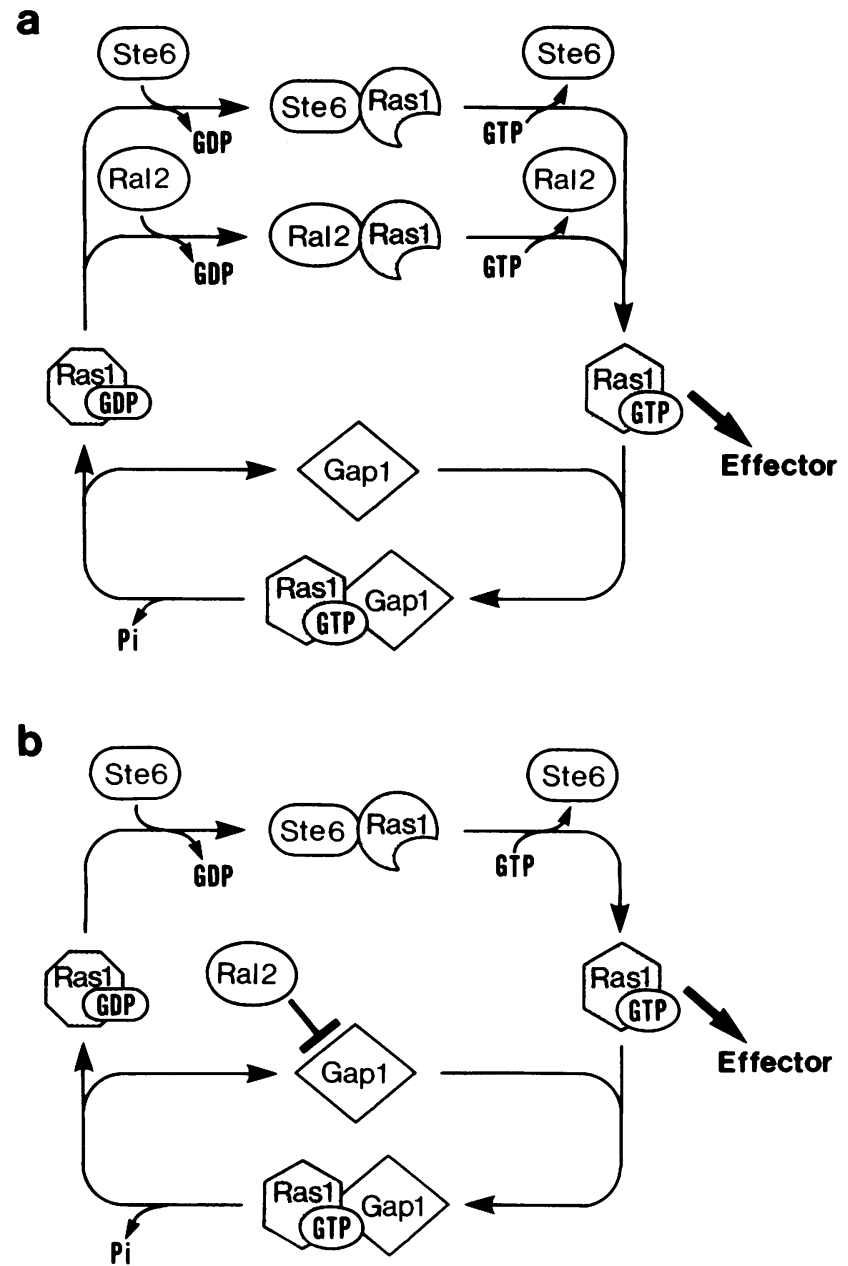

FIG. 5. Two alternative schemes for the Ras-GTPase cycle in $S$. pombe. Now that ste6 has been identified as an activator (22) and gapl has been identified as a negative regulator of Ras1, $S$. pombe has basically the same GTPase cycle as that diagrammed for $S$. cerevisiae (7). Assumption of different roles for another putative Ras1 activator, ral2, leads to two possible schemes. (a) Ste6 and Ral2 both function as GDP-GTP exchange proteins for Ras1. Ste6 and Ral2 may respond to different signals and may activate Ras1 to different levels. (b) The ral2 gene product can be a negative regulator of Gap1. This scheme is also consistent with the genetic data so far obtained.

cerevisiae (see reference 7), with $S$. pombe ste6 corresponding to $S$. cerevisiae $C D C 25(8,11,33)$ and $S$. pombe gapl corresponding to $S$. cerevisiae IRAI and IRA2 $(37,39)$, although the physiological role and the overall regulation of Ras are quite different in these two yeasts. However, since Cdc25 and Ste6 have regions with no similarity to each other over 600 amino acids and Ira1 and Ira 2 carry long N- and C-terminal sequences which Gap1 does not have, it is conceivable that the two yeasts perform distinct regulation of Ras through these differences. Although little is known about the molecular nature of such regulation, we recently obtained evidence that ste6 can convey the signal from environmental nitrogen starvation through its transcriptional activation (36a).

It has been reported that in $S$. cerevisiae, iral or ira 2 and $c d c 25$ function as mutual suppressors $(37,38)$. However, the gapl mutation was epistatic to the ste6 mutation in $S$. pombe, judging from the hypersensitivity of the cells to the mating factor. Even a combination of the ste6 and ral2 mutations did not alleviate the gapl mutation-induced phenotype. This suggests that loss of gapl function causes stronger effects than that of IRAI or IRA2. However, a more likely explanation for this is simply that Gap1 is the only Ras GTPase activator in $S$. pombe while Ira1 and Ira2 both function as GTPase activators in $S$. cerevisiae. It is essential to see the phenotype associated with iral ira2 cdc25 to explore this point further, but no report has dealt with it so far.

The role of Ral2, another putative Ras1 activator, in $S$. pombe, is not clear. It appears unlikely that mutations in ral2 cause effects by inhibiting expression of ras 1 , because point mutations in the rasl ORF can suppress ral2 efficiently, although direct measurement of the amount of Ras1 protein in ral2 mutant cells has not been done. On the basis of the genetic data obtained in this study, we propose two possible ways in which Ral2 may interact with the Ras GTPase cycle (Fig. 5). (i) Since the roles of ste6 and ral2 are genetically indistinguishable, the ral2 gene product could be another GDP-GTP exchange protein for Ras1. It appears unlikely that Ste6 and Ral2 function cooperatively as a complex, because ste6 and ral2 mutant cells have different cell morphologies (Fig. 5). Thus, the Ste6 and the Ral2 pathways may have distinct roles in the activation of Ras1, for instance, responding to different signals and activating Ras1 to different levels. This hypothesis predicts that both pathways should be turned on to induce sensitivity to the mating factor, although we should admit that it has not been substantiated that sensitivity is regulated in a dual manner in $S$. pombe. (ii) The other possible scheme is that the ral2 gene product causes positive effects on Ras1 because it negatively regulates Gap1 activity, which in turn negatively regulates Ras1 activity. This scheme explains the suppression of a ral2 mutation by a gapl mutation. Because ste6 and ral2 encode proteins sharing no homology, this possibility is undoubtedly worthy of examination. However, as discussed above, it is unclear whether $S$. pombe Gap1 is subject to complex regulation. Thus, the role of Ral2 remains a puzzling and intriguing question. Further investigation of the two hypothesized schemes may shed more light on the activation mechanisms of Ras proteins.

\section{ACKNOWLEDGMENTS}

We thank S. Nadin-Davis and A. Nasim for supplying an $S$. pombe strain. We also thank Y. Wang and M. Wigler of Cold Spring Harbor Laboratory for informing us of their independent isolation of an $S$. pombe gene with identical coding potential and of related results before publication.

This work was supported by grants-in-aid to M.Y. from the Ministry of Education, Science and Culture of Japan and the Mitsubishi Foundation. D.A.H. was supported by a Human Frontier Science Program long-term fellowship.

\section{REFERENCES}

1. Adari, H., D. R. Lowy, B. M. Willumsen, C. J. Der, and F. McCormick. 1988. Guanosine triphosphatase activating protein (GAP) interacts with the p21 ras effector binding domain. Science 240:518-521.

2. Anderson, D., C. A. Koch, L. Grey, C. Ellis, M. Moran, and T. Powson. 1990. Binding of $\mathrm{SH} 2$ domains of phospholipase $\mathrm{C}_{\gamma}-1$, GAP, and Src to activated growth factor receptors. Science 250:979-982.

3. Ballester, R., D. Marchuck, M. Boguski, A. Saulino, R. Letcher, M. Wigler, and F. Collins. 1990. The NFI locus encodes a 
protein functionally related to mammalian GAP and yeast IRA proteins. Cell 63:851-859.

4. Beach, D., M. Piper, and P. Nurse. 1982. Construction of a Schizosaccharomyces pombe gene bank in a yeast bacterial shuttle vector and its use to isolate genes by complementation. Mol. Gen. Genet. 187:326-329.

5. Beckner, S. K., S. Hattori, and T. Shih. 1985. The ras oncogene product p21 is not a regulatory component of adenylate cyclase. Nature (London) 317:71-72.

6. Birchmeier, C., D. Broek, and M. Wigler. 1985. RAS proteins can induce meiosis in Xenopus oocytes. Cell 43:615-621.

7. Bourne, H. R., D. A. Sanders, and F. McCormick. 1990. The GTPase superfamily: a conserved switch for diverse cell functions. Nature (London) 348:125-132.

8. Broek, D., T. Toda, T. Michaelis, L. Levin, C. Birchmeier, M. Zoller, S. Powers, and M. Wigler. 1987. The S. cerevisiae $C D C 25$ gene product regulates the $R A S /$ adenylate cyclase pathway. Cell 48:789-799.

9. Buchberg, A. M., L. S. Cleveland, N. A. Jenkins, and N. G. Copeland. 1990. Sequence homology shared by neurofibromatosis type-1 gene and $I R A-1$ and $I R A-2$ negative regulators of the $R A S$ cyclic AMP pathway. Nature (London) 347:291-294.

10. Cales, C., J. F. Hancock, C. J. Marshall, and A. Hall. 1988. The cytoplasmic protein GAP is implicated as the target for regulation by the ras gene product. Nature (London) 332:548-551

11. Camonis, J. H., M. Kalekine, B. Gongre, H. Garreau, E. Boy-Marcotte, and M. Jacquet. 1986. Characterization, cloning and sequence analysis of the $C D C 25$ gene which controls the cyclic AMP level of Saccharomyces cerevisiae. EMBO J. 5:375-380.

12. Dayhoff, M. O., R. M. Schwartz, and B. C. Orcutt. 1978. A model of evolutionary change in proteins, p. 345-352. In M. O. Dayhoff (ed.), Atlas of protein sequence and structure, vol. 5, suppl. 3. National Biomedical Research Foundation, Washington, D.C.

13. Egel, R., and M. Egel-Mitani. 1974. Premeiotic DNA synthesis in fission yeast. Exp. Cell Res. 88:127-134.

14. Fukui, Y., and Y. Kaziro. 1985. Molecular cloning and sequence analysis of a ras gene from Schizosaccharomyces pombe. EMBO J. 4:687-691.

15. Fukui, Y., Y. Kaziro, and M. Yamamoto. 1986. Mating pheromone-like diffusible factor released by Schizosaccharomyces pombe. EMBO J. 5:1991-1993.

16. Fukui, Y., T. Kozasa, Y. Kaziro, T. Takeda, and M. Yamamoto. 1986. Role of a ras homolog in the life cycle of Schizosaccharomyces pombe. Cell 44:329-336.

17. Fukui, Y., S. Miyake, M. Satoh, and M. Yamamoto. 1989. Characterization of the Schizosaccharomyces pombe ral2 gene implicated in activation of the rasl gene product. Mol. Cell. Biol. 9:5617-5622.

18. Fukui, Y., and M. Yamamoto. 1988. Isolation and characterization of Schizosaccharomyces pombe mutants phenotypically similar to rasl- Mol. Gen. Genet. 215:26-31.

19. Grimm, C., J. Kohli, J. Murray, and K. Maundrell. 1988. Genetic engineering of Schizosaccharomyces pombe: a system for gene disruption and replacement using the ura4 gene as a selectable marker. Mol. Gen. Genet. 215:81-86.

20. Gutz, H., H. Heslot, U. Leupold, and N. Loprieno. 1974. Schizosaccharomyces pombe, p. 395-446. In R. D. King (ed.), Handbook of genetics, vol. 1. Plenum Publishing Corp., New York.

21. Henikoff, S. 1984. Unidirectional digestion with exonuclease III creates targeted breakpoints for DNA sequencing. Gene 28:351359.

22. Hughes, D. A., Y. Fukui, and M. Yamamoto. 1990. Homologous activators of ras in fission and budding yeast. Nature (London) 344:355-357.

23. lino, Y., and M. Yamamoto. 1985. Mutants of Schizosaccharomyces pombe which sporulate in the haploid state. Mol. Gen. Genet. 198:416-421.

24. Kataoka, T., S. Powers, C. McGill, O. Fasano, J. Strathern, J. Broach, and M. Wigler. 1984. Genetic analysis of yeast RASI and $R A S 2$ genes. Cell 37:437-455.
25. Leupold, U. 1987. Sex appeal in fission yeast. Curr. Genet. 12:543-545.

26. Levitzki, A., J. Rudick, I. Pastan, W. C. Vass, and D. R. Lowy. 1986. Adenylate cyclase activity of NIH3T3 cells morphologically transformed by ras genes. FEBS Lett. 197:134-138.

27. Marshall, M. S., W. S. Hill, S. N. Assunta, U. S. Vogel, M. D. Schaber, E. M. Scolnick, R. A. F. Dixon, I. S. Sigal, and J. B. Gibbs. 1989. A C-terminal domain of GAP is sufficient to stimulate ras p21 GTPase activity. EMBO J. 8:1105-1110.

28. Martin, G. A., D. Viskochil, G. Bollag, P. C. McCabe, W. J. Crosier, H. Haubruck, L. Conroy, R. Clark, P. O'Connell, R. M. Cawthon, M. A. Innis, and F. McCormick. 1990. The Gaprelated domain of the neurofibromatosis type 1 gene product interacts with ras p21. Cell 63:843-849.

29. McCormick, F. 1989. ras GTPase activating protein: signal transmitter and signal terminator. Cell 56:5-8.

30. Nadin-Davis, S. A., A. Nasim, and D. Beach. 1986. Involvement of ras in sexual differentiation but not in growth control in fission yeast. EMBO J. 5:2963-2971.

31. Nadin-Davis, S. A., R. C. A. Yang, S. A. Narang, and A. Nasim. 1986. The cloning and characterization of a RAS gene from Schizosaccharomyces pombe. J. Mol. Evol. 23:41-51.

32. Okazaki, K., N. Okazaki, K. Kume, S. Jinno, K. Tanaka, and H. Okayama. 1990. High-frequency transformation method and library transducing vectors for cloning mammalian cDNAs by trans-complementation of Schizosaccharomyces pombe. $\mathrm{Nu}-$ cleic Acids Res. 18:6485-6489.

33. Robinson, L. C., J. B. Gibbs, M. S. Marshall, and K. Tatchell. 1987. $C D C 25$ : a component of the $R A S$-adenylate cyclase pathway in Saccharomyces cerevisiae. Science 235:1218-1221.

34. Rothstein, R. 1983. One step gene disruption in yeast. Methods Enzym. 101:202-211.

35. Sanger, F., S. Nicklen, and A. R. Coulson. 1977. DNA sequencing with chain-terminating inhibitors. Proc. Natl. Acad. Sci USA 74:5463-5467.

36. Sipiczki, M., and L. Ferenczy. 1977. Protoplast fusion of Schizosaccharomyces pombe auxotrophic mutants of identical mating-type. Mol. Gen. Genet. 151:77-81.

36a.Sugimoto, A., D. A. Hughes, and M. Yamamoto. Unpublished data.

37. Tanaka, K., K. Matsumoto, and A. Toh-e. 1989. IRAI, an inhibitory regulator of the $R A S$-cyclic AMP pathway in Saccharomyces cerevisiae. Mol. Cell. Biol. 9:757-768.

38. Tanaka, K., M. Nakafuku, T. Satoh, M. Marshall, J. Gibbs, K. Matsumoto, Y. Kaziro, and A. Toh-e. 1990. S. cerevisiae genes IRAI and IRA2 encode proteins that may be functionally equivalent to mammalian ras GTPase activating protein. Cell 60:803-807.

39. Tanaka, K., M. Nakafuku, F. Tamanoi, Y. Kaziro, K. Matsumoto, and A. Toh-e. 1990. IRA2, a second gene of Saccharomyces cerevisiae that encodes a protein with a domain homologous to mammalian ras GTPase-activating protein. Mol. Cell. Biol. 10:4303-4313.

40. Tatchell, K., D. T. Chaleff, D. DeFeo-Jones, and E. M. Scolnick. 1984. Requirement of either of a pair of ras-related genes of Saccharomyces cerevisiae for spore viability. Nature (London) 309:523-527.

41. Toda, T., I. Uno, T. Ishikawa, S. Powers, T. Kataoka, D. Broek, S. Cameron, J. Broach, K. Matsumoto, and M. Wigler. 1985. In yeast, RAS proteins are controlling elements of adenylate cyclase. Cell 40:27-36.

42. Trahey, M., and F. McCormick. 1987. A cytoplasmic protein stimulates normal N-ras p21 GTPase, but does not affect oncogenic mutants. Science 238:542-545.

43. Trahey, M., G. Wong, R. Halenbeck, B. Rubinfeld, G. Martin, M. Ladner, C. Long, W. Crosier, K. Watt, K. Koths, and F. McCormick. 1988. Molecular cloning of two types of GAP complementary DNA from human placenta. Science 242:16971700.

44. Vogel, U. S., R. A. F. Dixon, M. D. Schaber, R. E. Diehl, M. S. Marshall, E. M. Scolnick, I. S. Sigal, and J. B. Gibbs. 1988 Cloning of bovine GAP and its interaction with oncogenic ras p21. Nature (London) 335:90-93. 
45. Watanabe, Y., Y. Iino, K. Furuhata, C. Shimoda, and $M$. Yamamoto. 1988. The $S$. pombe mei2 gene encoding a crucial molecule for commitment to meiosis is under the regulation of cAMP. EMBO J. 7:761-767.

46. Xu, G., B. Lin, K. Tanaka, D. Dunn, D. Wood, R. Gesteland, R. White, R. Weiss, and F. Tamanoi. 1990. The catalytic domain of the neurofibromatosis type 1 gene product stimulates ras
GTPase and complements ira mutants of S. cerevisiae. Cell 63:835-841.

47. Xu, G., P. O'Connell, D. Viskochil, R. Cawthon, M. Robertson, M. Culver, D. Dunn, J. Stevens, R. Gesteland, R. White, and R. Weiss. 1990. The neurofibromatosis type 1 gene encodes a protein related to GAP. Cell 62:599-608. 